\title{
UTILIZAÇÃO DE RECURSOS TECNOLÓGICOS NAS AULAS DE FÍSICA COMO FORMA DE SUPERAR AS DIFICULDADES IMPOSTAS PELA PANDEMIA DA COVID-19
}

\author{
USE OF TECHNOLOGICAL RESOURCES IN PHYSICS CLASSES AS A WAY TO \\ OVERCOME THE DIFFICULTIES IMPOSED BY THE COVID-19 PANDEMIC
}

\author{
USO DE RECURSOS TECNOLÓGICOS EN CLASES DE FÍSICA COMO FORMA \\ DE SUPERAR LAS DIFICULTADES IMPUESTAS POR LA PANDEMIA COVID-19
}

\author{
Jean Louis Landim Vilela* (D) 9 \\ Anderson Claiton Ferraz ** (D) 0 \\ Mauro Sérgio Teixeira de Araújo ${ }^{* * *}$ (D) $(9$
}

\begin{abstract}
RESUMO
Este artigo constitui-se em um estudo exploratório realizado em um contexto aonde a inserção da tecnologia na vida da população mudou significativamente seus hábitos e atitudes. Tendo a educação como um dos setores mais impactados por essas transformações, entende-se que professores e alunos necessitam se reestruturar frente às novas metodologias de ensino, cada vez mais marcadas pela presença de recursos tecnológicos nas atividades escolares. Com o advindo da Covid-19 a necessidade de mudança tornou-se mais urgente ainda, porém será que estávamos preparados? O objetivo deste trabalho foi identificar em alunos de escolas públicas e privadas, de Minas Gerais e São Paulo, suas percepções quanto à utilização de recursos tecnológicos durante a pandemia nas aulas de Física. Para isto, foi aplicado um questionário contendo questões abertas e fechadas, utilizando o google formulários, sendo as questões abertas categorizadas a posteriori com base na Análise de Conteúdo de Bardin. Os resultados indicaram que a utilização de recursos tecnológicos contribuiu com as aulas online, devido a diversidade de instrumentos que a internet oferece e o auxílio de vídeo aulas. Porém, uma parcela dos alunos apontou dificuldades em compreender os conteúdos abordados e falta de concentração nas aulas. O comprometimento relacionado ao interesse e responsabilidade com as atividades propostas foi destacado pelos alunos, sendo que alguns relataram maior desinteresse, além de sentirem necessidade da presença física do professor. Concluímos que os recursos tecnológicos permitiram que as aulas pudessem ocorrer mesmo no contexto de isolamento provocado pela Covid-19, contribuindo para a aprendizagem e envolvimento da maioria dos estudantes.
\end{abstract}

Palavras-chave: Recursos Tecnológicos. Formação de Professores. Pandemia de COVID-19.

\footnotetext{
* Doutorando em Ensino de Ciências e Matemática na Universidade Cruzeiro do Sul (UNICSUL). Professor da Educação Básica, pública e privada, Caxambu, Minas Gerais, Brasil. Rua Professor José Marcos da Motta, 98, Bela Vista, Caxambu - MG. CEP: 37440-000. vilelalandim@ hotmail.com.

** Doutorando em Ensino de Ciências e Matemática na Universidade Cruzeiro do Sul (UNICSUL). Professor da Educação Básica do Estado de São Paulo, Salto de Pirapora, São Paulo, Brasil. Rua Malvina Antunes de Oliveira, 221. Bairro Ilha das Flores, Salto de Pirapora, São Paulo. CEP: 18160-000. biromau2006@yahoo.com.br.

*** Doutor em Ciências pelo Instituto de Física da USP (IFUSP). Professor Titular (UNICSUL) São Paulo - SP, Brasil. Rua Tuiuti, 589 Ap. 153 Bloco 4, Tatuapé - São Paulo - SP. CEP: 03081-003. mstaraujo@uol.com.br.
} 


\begin{abstract}
This article is an exploratory study carried out in a context where the insertion of technology in the lives of the population has significantly changed their habits and attitudes. With education as one of the sectors most impacted by these transformations, it is understood that teachers and students need to restructure in the face of new teaching methodologies, increasingly marked by the presence of technological resources in school activities. With the advent of Covid-19, the need for change has become even more urgent, but were we prepared? The objective of this study was to identify in students from public and private schools, in Minas Gerais and São Paulo, their perceptions regarding the use of technological resources during the pandemic in Physics classes. For this, a questionnaire containing open and closed questions was applied, using google forms, and the open questions were categorized a posteriori based on Bardin's Content Analysis. The results indicated that the use of technological resources contributed with the online classes, due to the diversity of tools that the internet offers and the help of video classes. However, a portion of the students pointed out difficulties in understanding the contents covered and a lack of concentration in the classes. The commitment related to interest and responsibility with the proposed activities was highlighted by the students, and some of them reported a greater lack of interest, besides feeling the need for the teacher's physical presence. We conclude that the technological resources allowed the classes to take place even in the context of isolation caused by Covid-19, contributing to the learning and involvement of most students.
\end{abstract}

Keywords: Technological Resources. Teacher Training. Pandemic of COVID-19.

\title{
RESUMEN
}

Este artículo es un estudio exploratorio realizado en un contexto donde la inserción de la tecnología en la vida de la población ha cambiado de modo significativo sus hábitos y costumbres. Con la educación como uno de los sectores más afectados por esos cambios, se entiende que docentes y estudiantes, necesitan reestructurarse de cara a nuevas metodologías de enseñanza, cada vez más marcadas por la presencia de recursos tecnológicos en las actividades escolares. Con la llegada del Covid-19, la necesidad de cambio se volvió aún más urgente, pero ¿estábamos preparados? El objetivo de este trabajo fue identificar en estudiantes de la enseñanza públicas y privadas, de Minas Gerais y São Paulo, sus percepciones sobre el uso de recursos tecnológicos durante la pandemia en las clases de Física. Para ello, se aplicó un cuestionario de preguntas abiertas y cerradas, utilizando formularios de Google con preguntas abiertas clasificadas a posteriori con base en el Análisis de Contenido de Bardin. Los resultados indicaron que el uso de recursos tecnológicos contribuyó a las clases online, debido a la diversidad de herramientas ofrecidas por internet y las lecciones en vídeo. Sin embargo, una parte de los estudiantes señaló dificultades en la comprensión de los contenidos tratados y falta de concentración en las clases. El compromiso relacionado con el interés y la responsabilidad con las actividades propuestas fue resaltado por los estudiantes, con algunos reportando mayor desinterés, además de sentir la necesidad de la presencia física del docente. Concluimos que los recursos tecnológicos permitieron que las clases se llevaran a cabo incluso en el contexto de aislamiento causado por el Covid-19, contribuyendo al aprendizaje y la participación de la mayoría de los estudiantes.

Palabras clave: Recursos tecnológicos. Formación de professores. Pandemia de COVID-19.

\section{INTRODUÇÃO}

Atualmente a sociedade vivencia um avanço tecnológico sem precedentes, sendo que a presença de dispositivos eletrônicos muitas vezes é exagerada, podendo causar dependência tecnológica nos cidadãos. Por outro lado, a Ciência e a Tecnologia se renovam a cada dia, 
permitindo aprimorar e desenvolver novos equipamentos que visam suprir as demandas da sociedade. Neste sentido, Bazzo (1998) destaca que:

É inegável a contribuição que a ciência e a tecnologia trouxeram nos últimos anos. Porém, apesar desta constatação, não podemos confiar excessivamente nelas, tornando-nos cegos pelo conforto que nos proporcionam cotidianamente seus aparatos e dispositivos técnicos [...]. (BAZZO, 1998, p.142).

A Tecnologia está presente nos mais variados ambientes do nosso cotidiano, como nas casas, nos sistemas de transporte, bancos e também nas escolas. A sociedade está cada vez mais cercada por instrumentos tecnológicos, com destaque para os celulares e seus aplicativos, recursos capazes de contribuir para a realização de muitas atividades cotidianas, mas que também podem prejudicar as vidas e ações dos indivíduos. A população jovem tende a ser a mais influenciada pela Tecnologia, que influencia seus hábitos, suas atitudes e a maneira de agir, particularmente no que se refere aos ambientes escolares, onde se envolvem com as atividades de escolarização sob influência da Tecnologia. Arocena (2004) ao abordar a questão da Tecnologia assim salienta seus benefícios e malefícios:

A tecnologia tem multiplicado e transformado qualitativamente o poder de produzir e destruir, de curar e depredar, de ampliar a cultura dos seres humanos e de gerar riscos para a vida, sendo que esse poder associado aos perigos está distribuído social e regionalmente, de maneira muito desigual (AROCENA, 2004, p.208).

A utilização das tecnologias no ambiente escolar é um desafio constante para os professores, que precisam se adequar as constantes mudanças para poderem contribuir com uma aprendizagem adequada dos alunos. A Tecnologia deve ser usada para enriquecer o ambiente educacional e favorecer a aprendizagem, constituindo um recurso valorizado pelos discentes. Recursos como TV, datashow, lousas digitais, internet, celular, computadores, dentre outros, tendem a ser cada vez mais importantes para aprimorar as aulas e despertar o interesse dos estudantes. Neste sentido, Moran (2000, p.17-18) destaca que "[...] alunos curiosos e motivados facilitam enormemente o processo, estimulam as melhores qualidades do professor, tornam-se interlocutores lúcidos e parceiros de caminhada do professor-educador [...]”".

A utilização de recursos tecnológicos é enfatizada pela BNCC (BRASIL, 2017), que destaca entre as competências gerais a serem desenvolvidas na Educação Básica: 
conhecimentos, resolver problemas e exercer protagonismo e autoria na vida pessoal e coletiva. (BRASIL, 2017, p. 9).

As mudanças e aprimoramentos na prática docente com base em recursos tecnológicos têm o intuito de promover uma educação mais dinâmica, estimulando o envolvimento dos estudantes, embora gere nos professores algumas dificuldades, ocasionando situações de eventual desinteresse. Para Burochovitch e Bzuneck (2004, p. 13) é preciso valorizar a motivação, pois ela "tornou se um problema de ponta em educação, pela simples constatação de que, em paridade de outras condições, sua ausência representa queda de investimento pessoal de qualidade nas tarefas de aprendizagem".

Nesse cenário de desafios onde é preciso superar diversos problemas, a Educação brasileira se viu recentemente diante de um contexto de pandemia que obrigou todas as instituições de ensino do país a se adequarem, readaptando as formas de ensinar os conteúdos aos seus alunos. A Covid-19 que significa - Corona Vírus Disease - (Doença do Coronavírus) é uma doença respiratória causada por um vírus $S A R S-C o V-2$ e apresenta como principais sintomas febre, tosse seca e dificuldade respiratória. Essa doença é transmitida de uma pessoa para outra por meio de gotículas respiratórias e para prevenir o contágio é recomendado, entre outras medidas, evitar aglomerações. Neste contexto, escolas, universidades e instituições de ensino foram fechadas e tiveram que planejar e implantar maneiras alternativas dos professores trabalharem.

Diante dessa realidade, o intuito do presente trabalho é identificar alguns efeitos da pandemia, investigando como os alunos do Ensino Médio de escolas públicas e privadas analisam este contexto, particularmente no que se refere à área de ensino de Física. Para isto, temos a seguinte questão norteadora: "Quais são as percepções dos estudantes de escolas públicas e privadas quanto ao uso de recursos tecnológicos durante o período da pandemia de Covid-19?"

Frente a esse questionamento destacamos que o objetivo desse artigo é apontar possíveis dificuldades, angústias e fatores que podem afetar a aprendizagem de Física na visão de alguns discentes da Educação Básica no período da pandemia da Covid-19.

Cabe ressaltar que este trabalho constitui uma pesquisa exploratória, modalidade de pesquisa utilizada quando se deseja obter dados de um problema (TONETTO et al., 2014) e com isso analisar todas as intenções dos participantes. Por sua vez, Vieira (2002, p. 65) salienta que: 


\begin{abstract}
A pesquisa exploratória visa a proporcionar ao pesquisador uma maior familiaridade com o problema em estudo [...]. Como o nome sugere, a pesquisa exploratória procura explorar um problema ou uma situação para prover critérios e compreensão. A pesquisa exploratória utiliza métodos bastante amplos e versáteis.
\end{abstract}

Os procedimentos de análise dos dados obtidos na pesquisa foram norteados pela Análise do Conteúdo de Bardin (2010) apresentando, portanto, um caráter qualitativo e buscando-se trabalhar com interpretações dos fenômenos e fornecendo um maior enfoque para a etapa de categorização.

\title{
2 REFERENCIAL TEÓRICO
}

\section{A contribuição da Tecnologia para a formação dos estudantes durante a pandemia}

A ampla utilização da Tecnologia nas atividades escolares está afetando a relação entre professores e alunos e dadas as dificuldades enfrentadas por alguns docentes no uso dos recursos tecnológicos observa-se um afastamento destes em relação à realidade em que normalmente os alunos estão inseridos. A utilização das tecnologias no contexto escolar, em especial nas Ciências, pode ser um caminho para uma reaproximação e despertar dos alunos para as conexões entre os conteúdos curriculares abordados e de seu interesse em trabalhá-los. Porém, é importante destacar que não basta o professor vincular o conhecimento científico com a Tecnologia, é preciso que ele avance em relação ao significado da Ciência e da Tecnologia na sociedade atual (BAZZO, 1998). Neste sentido, Strieder et al. (2012, p. 161) destaca que:

\footnotetext{
O funcionamento dos aparatos tecnológicos é importante e poderia ser um ponto de partida a ser utilizado, contudo, para uma efetiva compreensão do tema é necessário que sejam tratadas questões mais amplas, como, por exemplo, as causas e as consequências da fabricação e utilização de determinadas tecnologias.
}

Portanto, para que essa abordagem ocorra é fundamental que os professores aperfeiçoem a sua formação e possam fazer uso adequado da Tecnologia, favorecendo aos estudantes a produção de novos conhecimentos, ampliando seu desenvolvimento intelectual e aprimorando a relação com os alunos. Por meio dessa formação, os professores poderão atender as necessidades pedagógicas atuais e com isso contemplar as demandas que os alunos carregam consigo no dia a dia, aumentando o interesse pelas aulas. Strieder et al. (2016, p. 58) entende que a formação de professores "não deve ser pensada como um 'treinamento' para que os professores implementem de forma correta conhecimentos produzidos em outras instâncias". Para Strieder et al. (2016, p.58) “ela deve ser desenvolvida na perspectiva da parceria 
colaborativa entre pesquisadores, professores da educação básica e licenciando, ambos buscando soluções para problemas enfrentados nas escolas".

Diante do cenário da pandemia de Covid-19 os professores de diversos segmentos da Educação Brasileira foram obrigados a passar por um processo de formação para que pudessem mudar a sua forma de abordar os conteúdos escolares. Este é um exemplo de como a Ciência e a Tecnologia conseguem mudar de forma marcante o comportamento da sociedade, alterando a maneira de agir dos estudantes ao promover novas formas de aquisição de conhecimentos no período da pandemia. Santos et al (2006, p. 71) ressalta que a formação deve "procurar construir caminhos que vislumbrem as exigências associadas ao perfil do profissional que se pretende habilitar para a tarefa de educar visando ao exercício da cidadania”, aspecto que é reforçado por Moraes e Araújo (2012, p. 27) ao afirmarem que "um dos objetivos principais da Educação, que é formar para a vida, para o exercício adequado e consciente da cidadania”.

Entendemos que a superação das aulas convencionais de Física representa um grande desafio aos docentes, tendo em vista que elas tendem a gerar falta de interesse e desmotivação por parte dos alunos, que passam a ter dificuldades em compreender os conceitos abordados e estabelecer relações entre estes conteúdos e a sua realidade de vida, prejudicando com isso sua aprendizagem e desenvolvimento. Diante deste cenário já desafiador para o ensino de Física, soma-se as dificuldades decorrentes do fato do professor necessitar fazer uso de recursos tecnológicos em sua atividade docente, constituindo-se frequentemente estes recursos a principal ferramenta para abordar os conteúdos escolares. O enfrentamento destes desafios é relevante por diversos fatores e, neste sentido, Neide et al. $(2019$, p.580) destaca que "trabalhar com tecnologias deve ser algo motivacional para o aprendizado do aluno, pois possibilita uma visão diferente daquela que ele está habituado, mostrando que a Física não se resume a fórmulas e temas fragmentados".

Portando, dado o cenário de maior isolamento social, aulas empregando plataformas digitais, aplicativos de celulares, lives para debates, canais do youtube, aplicativos de trocas de mensagens, dentre outros, foram recursos que os professores tiveram que utilizar para que os conteúdos disciplinares pudessem chegar até seus alunos.

A educação em geral e particularmente neste contexto de maior uso de recursos tecnológicos deve ter como objetivo formar um cidadão atuante na sociedade, capaz de agir com autonomia e tomar decisões amparadas em valores éticos que possam orientar suas atitudes em prol de uma melhor qualidade de vida, tendo ainda por base os conhecimentos decorrentes 
das atividades científicas e tecnológicas. Nesse sentido, Santos e Mortimer (2000, p. 118) destaca que:

\begin{abstract}
A educação tecnológica no ensino vai muito além do fornecimento de conhecimentos limitados de explicação técnica do funcionamento de determinados artefatos tecnológicos. Não se trata de simplesmente preparar o cidadão para saber lidar com essa ou aquela ferramenta tecnológica ou desenvolver no aluno representações que o instrumentalize a absorver as novas tecnologias.
\end{abstract}

Considerando o contexto atual, em que a pandemia de Covid-19 impôs mudanças na forma das pessoas interagirem com segurança, no âmbito educacional a construção de conhecimentos durante as aulas constitui um grande desafio para os professores ou futuros professores, cenário este que é agravado pelo fato de muitos alunos não possuírem os devidos recursos para acessar as aulas, não possuem um computador ou mesmo um celular para acompanhar as devidas orientações. Além disso, há grande insegurança por parte de vários alunos em relação ao manuseio de aplicativos propostos para acessar as aulas e em muitas situações ainda é escasso o acesso à internet, aspectos que ampliam as dificuldades para que o ensino de Física e Ciências em geral aconteça satisfatoriamente.

Por outro lado, existem também vantagens em se poder utilizar a Tecnologia como ferramenta para aulas online, uma vez que o aluno passa a ter maior autonomia para acompanhar as aulas, assumindo uma maior responsabilidade diante das atividades propostas. Pesa ainda a favor a presença de um grande número de recursos digitais, com materiais atualizados e a possibilidade de acontecer uma maior interação entre os colegas de turma e destes com o professor, auxiliando na troca de experiências e construção de conhecimentos. Corroborando com este cenário de mudanças em parte reforçadas pelo atual momento de pandemia, Araújo (2011) ressalta a necessidade de ocorrerem transformações do modelo educacional afirmando que:

\footnotetext{
Os profissionais da educação precisam entender e assumir uma postura acadêmicocientífica que leve à reinvenção da educação. Esse modelo de escola e de universidade consolidado no século XIX tem agora, também, de dar conta das demandas e necessidades de uma sociedade democrática, inclusiva, permeada pelas diferenças e pautada no conhecimento inter, multi e transdisciplinar, como a que vivemos neste início de século XXI (ARAÚJO, 2011, p. 39).
}

Diante dessa realidade, é tarefa do profissional docente conferir à escola e à Educação a qualidade que todos almejamos, cabendo aos professores realizar uma análise crítica, inovadora e permanente de sua prática, considerando a formação continuada a partir das 
necessidades locais, em consonância com as diretrizes propostas em documentos oficiais norteadores para que se promova o desenvolvimento dos estudantes (SEE/MG, 2019).

\section{METODOLOGIA}

A pesquisa contou com a aplicação de um questionário para alunos do Ensino Médio da rede pública e privada de escolas de Minas Gerais. O questionário foi respondido por 129 alunos pertencentes a turmas de primeiro, segundo e terceiro anos, sendo 78 alunos de escolas públicas e 51 de escolas privadas. Segundo Gil (1999, p.128), um questionário pode ser definido "como a técnica de investigação composta por um número mais ou menos elevado de questões apresentadas por escrito às pessoas, tendo por objetivo o conhecimento de opiniões, sentimentos, interesses, expectativas, etc.”.

Os alunos responderam às perguntas, das quais as três questões abertas farão parte da narrativa específica aqui apresentada. A confecção do questionário empregou o Google formulários, um recurso que está disponível de forma gratuita e que necessita apenas de uma conta de e-mail da Google. Após a criação do questionário foi gerado um link que foi enviado aos alunos através de grupos de Whatsapp. Todas as respostas fornecidas ficam armazenadas na nuvem e para o aplicador do questionário acessá-las basta utilizar a conta de e-mail cadastrada e procurar pela ferramenta formulários. Os alunos tiveram 5 dias para responderem e não havia necessidade de se identificarem, possibilitando maior liberdade para se manifestarem.

Após a obtenção das respostas, as questões abertas foram categorizadas, utilizando como aporte teórico a Análise de Conteúdo de Bardin (2010, p. 280), sendo desenvolvidas "as seguintes etapas para a sua condução: organização da análise; categorização; tratamento dos resultados e a interpretação deles". Para isto, foi realizada a leitura de todas as respostas, identificando os elementos de significado e posteriormente procedendo à sua categorização.

Conforme descrição de Bardin (2011), optamos por estabelecer a categorização $a$ posteriori dos itens analisados. Segundo a autora, a atividade taxonômica é uma operação muito vulgarizada de repartição dos objetos em categorias e o critério para o estabelecimento destas é adaptado à realidade do investigador (BARDIN, 2011, p.147-148).

As categorias emergiram do processo de análise das respostas dadas às questões abertas e contou com a participação de 129 alunos, ou seja, foram categorias criadas a posteriori, sendo que cada uma delas deu origem a subcategorias. 
A análise das questões abertas levou em consideração três situações: a primeira se os alunos consideravam que os recursos tecnológicos são úteis para a aprendizagem do conteúdo de Física; a segunda, quais são as maiores dificuldades observadas para acompanhar as aulas de Física no período da pandemia; e a terceira, se no período de pandemia, a Tecnologia modificou o comportamento dos estudantes durante as aulas. Em cada questionamento os alunos tinham a liberdade de responder e justificar, embora nem todas as respostas tenham sido acompanhadas de justificativas.

As aulas ministradas pelos professores no período da pandemia foram síncronas, utilizando como plataforma o Google Meet, seguindo o horário proposto pelas escolas no início do ano letivo. Deste modo, os alunos recebiam o link de acesso para cada aula e a interação ocorria em tempo real.

\section{ANÁLISES E RESULTADOS}

A primeira questão tinha como enunciado "Você considera que os recursos tecnológicos são úteis para colaborar na aprendizagem dos conteúdos de Física? Justifique.”. A tabela 1 representa as categorias e subcategorias que surgiram a posteriori e o número das respostas fornecidas pelos alunos.

Tabela 1 - Utilidade dos recursos tecnológicos para a aprendizagem dos conteúdos de Física.

\begin{tabular}{|c|c|c|c|}
\hline Categorias & Subcategorias & $\mathrm{N}^{\circ}$ de respostas & Total \\
\hline \multirow{4}{*}{$\begin{array}{l}\text { Vantagens dos recursos } \\
\text { tecnológicos }\end{array}$} & Maior diversidade de recursos na internet & 23 & \multirow{4}{*}{53} \\
\hline & Auxílio de vídeo aula & 17 & \\
\hline & $\begin{array}{l}\text { Maior auxílio dos professores por meio das } \\
\text { redes sociais }\end{array}$ & 09 & \\
\hline & Melhor compreensão do conteúdo abordado & 04 & \\
\hline \multirow{4}{*}{$\begin{array}{l}\text { Problemas enfrentados } \\
\text { com os recursos } \\
\text { tecnológicos }\end{array}$} & Dificuldade na aprendizagem & 19 & \multirow{4}{*}{36} \\
\hline & Falta da presença física do professor & 11 & \\
\hline & Desatenção dos alunos & 05 & \\
\hline & Não tem acesso a plataformas digitais & 01 & \\
\hline
\end{tabular}

Fonte: dos autores. 
A primeira categoria emergente retrata as vantagens proporcionadas pelo uso dos recursos tecnológicos na concepção dos alunos, com um total de 53 respostas. Essa categoria deu origem a quatro subcategorias, contendo a primeira delas 23 respostas e destacando que os alunos consideram importante a internet como ferramenta auxiliar nos estudos devido à grande diversidade de recursos e informações, o que favorece a compreensão dos conteúdos abordados pelo professor. Esta percepção se alinha com o que defende Moran (2007b) ao afirmar que:

As tecnologias são pontes que abrem a sala de aula para o mundo, que representam, medeiam o nosso conhecimento do mundo. São diferentes formas de representação da realidade, de forma mais abstrata ou concreta, mais estática ou dinâmica, mais linear ou paralela, mas todas elas, combinadas, integradas, possibilitam uma melhor apreensão da realidade e o desenvolvimento de todas as potencialidades do educando, dos diferentes tipos de inteligência, habilidades e atitudes (MORAN, 2007b, p. 164).

Portanto, a internet possibilita para o aluno a liberdade de aprofundar seus estudos e ampliar seus conhecimentos, permitindo-lhe fazer novas buscas e sanar suas dúvidas.

O quadro a seguir retrata algumas manifestações dos alunos em relação a diversidade de recursos oferecidos pela internet.

\begin{tabular}{|cl|}
\hline Aluno & Transcrição \\
\hline $\mathbf{A}_{1}$ & $\begin{array}{l}\text { Com esses recursos podemos assistir vídeo aula, resolução comentada sobre exercícios, etc. } \\
\mathbf{A}_{2}\end{array}$ \\
$\begin{array}{l}\text { A internet é uma ajuda e tanto, principalmente para quem tem dificuldade e tem acesso a milhares de } \\
\text { informações através dos recursos tecnológicos. }\end{array}$ \\
$\begin{array}{l}\text { Aorque nessa época que estamos vivendo a internet é a nossa principal aliada para obter } \\
\text { conhecimento. }\end{array}$ \\
$\begin{array}{l}\text { Pois facilita na procura de assuntos e previne que outros alunos e profissionais da educação sejam } \\
\text { contagiados pelo covid-19. }\end{array}$ \\
$\begin{array}{l}\text { Apesar de não se igualar as aulas presenciais, são muito úteis e acredito que estamos tirando o maior } \\
\text { proveito possível. }\end{array}$ \\
\hline
\end{tabular}

Quadro 1 - Manifestações dos alunos em relação à diversidade de recursos proporcionados pela internet. Fonte: Elaborada pelos autores.

A segunda subcategoria destaca a utilização de vídeo aula por parte dos estudantes, que a entendem como um recurso muito utilizado e que possibilita dirimir possíveis incompreensões em relação ao tema discutido pelo professor, contribuindo para que possam relacionar tais assuntos com aspectos políticos, sociais, econômicos, éticos, ambientais, etc. As vídeo aulas eram disponibilizadas aos alunos já gravadas e o acesso a elas poderia ser feito por meio do youtube ou das próprias aulas do Google Meet que eram gravadas pelos professores. Segundo Dallacosta et al. (2004): 
A vídeo aula quando bem planejada consegue fazer com que os alunos participem ativamente, muitas vezes procurando certo conteúdo que os professores tem dificuldade de encontrar devido às diversidades e acessibilidade de fontes de informações em nossa sociedade (DALLACOSTA et al., 2004, p.1).

A seguir, o Quadro 2 representa algumas manifestações dos alunos em relação à utilização das vídeo aulas.

\begin{tabular}{|c|c|}
\hline Aluno & Transcrição \\
\hline A6 & $\begin{array}{l}\text { Quando não entendo algo nas aulas virtuais, sempre posso estar buscando outras aulas do mesmo } \\
\text { assunto. }\end{array}$ \\
\hline $\mathbf{A}_{7}$ & Com a ajuda das vídeo aulas fica mais fácil o entendimento das matérias. \\
\hline As & $\begin{array}{l}\text { Vídeo aulas são extremamente importantes pra mim, já que sou de humanas e levo um certo tempo a } \\
\text { mais para pegar a matéria. }\end{array}$ \\
\hline A9 & $\begin{array}{l}\text { A vantagem é que existem várias formas de estudar e há uma variedade de vídeos e exercícios de } \\
\text { Física. }\end{array}$ \\
\hline $\mathbf{A}_{10}$ & Em caso de dúvidas é mais fácil para poder voltar e revisar, mas não substitui as aulas presenciais. \\
\hline
\end{tabular}

Quadro 2 - Manifestações dos alunos em relação à utilização de vídeo aula. Fonte: Elaborada pelos autores.

A terceira subcategoria está relacionada com apontamentos feitos pelos alunos que consideram útil o maior auxílio dos professores por meio das redes sociais, aspecto destacado por 9 alunos. As redes sociais facilitam a interação professor-aluno, pois através de aplicativos como whatsapp e facebook dúvidas foram sanadas e mensagens enviadas, possibilitando o envio de arquivos (imagens, áudios, vídeos ou documentos), facilitando o trabalho de muitos professores. Kenski (2007, p. 103) alerta para as contribuições da Tecnologia asseverando que:

Professor e aluno formam "equipes de trabalho" e passam a ser parceiros de um mesmo processo de construção e aprofundamento do conhecimento: aproveitar o interesse natural dos jovens estudantes pelas tecnologias e utilizá-las para transformar a sala de aula em espaço de aprendizagem ativa e de reflexão coletiva; capacitar os alunos não apenas para lidar com as novas exigências do mundo do trabalho, mas, principalmente, para a produção e manipulação das informações e para o posicionamento crítico diante dessa nova realidade.

O quadro 3 retrata a fala de alguns alunos sobre o auxílio que receberam com base na utilização de mensagens enviadas via aplicativos, no intuito de auxiliar a compreensão dos conteúdos trabalhados. 


\begin{tabular}{|cl|}
\hline Aluno & Transcrição \\
\hline $\mathbf{A}_{11}$ & As tutorias online com os professores e a utilização dos ambientes virtuais são muito produtivas! \\
$\mathbf{A}_{12}$ & Vídeo aulas e mensagens de texto com o professor auxiliam muito. \\
$\mathbf{A}_{13}$ & $\begin{array}{l}\text { O professor usa todos os recursos disponíveis que são excelentes e nos ajudam muito. } \\
\mathbf{A}_{14}\end{array}$ \\
$\begin{array}{l}\text { Como a Física é uma matéria bem difícil pra alguns alunos, aprender pela internet não gera um } \\
\text { resultador do que presencial e necessitamos mais do auxílio do professor. }\end{array}$ \\
$\begin{array}{l}\text { Quando não entendo algo nas aulas virtuais, sempre posso estar buscando outras aulas do mesmo } \\
\text { assunto e ter auxílio do professor através de mensagens pelo whatsapp. }\end{array}$ \\
\hline
\end{tabular}

Quadro 3 - O auxílio dos professores aos alunos e a utilização de mensagens de texto.

Fonte: Elaborada pelos autores.

Na última subcategoria os alunos relataram que a utilização de recursos tecnológicos é capaz de melhorar a compreensão do conteúdo trabalhado, aspecto apontado por 4 alunos. Neste sentido, Almeida (2011) destaca que utilizar ferramentas tecnológicas contribui para a busca da qualidade da educação.

\begin{tabular}{|cl|}
\hline Aluno & Transcrição \\
\hline \multirow{2}{*}{$\begin{array}{l}\text { Esses recursos utilizados facilitaram o meu entendimento da matéria de forma eficaz dado em } \\
\text { consideração a situação atual. }\end{array}$} \\
$\begin{array}{l}\text { Aenho algumas dificuldades em compreender os assuntos de Física, mas considero que as } \\
\text { ferramentas utilizadas nas aulas online estão ajudando e muito. }\end{array}$ \\
$\quad \begin{array}{l}\text { Acho que quando as aulas retornarem o professor poderia continuar usando a internet, para nos } \\
\text { ajudar a aprender mais. }\end{array}$ \\
\hline
\end{tabular}

Quadro 4 - Vantagens da utilização dos recursos tecnológicos para o aprendizado.

Fonte: Elaborada pelos autores.

A segunda categoria de análise destaca os Problemas enfrentados com o uso dos recursos tecnológicos pelos alunos, relatados por 36 deles. Dentre as subcategorias identificadas, a dificuldade na aprendizagem é a que mais se destacou, com 19 respostas. Os recursos tecnológicos trouxeram grande impacto para a Educação e para a vida dos alunos, havendo muitos fatores que afetam negativamente a aprendizagem e, consequentemente, geram prejuízos na compreensão dos conteúdos. Para Costa (2015), as novas tecnologias não são garantia de aprendizagem pois, na prática, muitas vezes elas não são utilizadas e quando isto ocorre pode ser feita sem a adequada abordagem pedagógica, resumindo-se apenas em um acessório, não corresponde a expectativa dos alunos. Os relatos a seguir, no Quadro 5, destacam algumas das dificuldades apontadas pelos alunos investigados. 


\begin{tabular}{|cl|}
\hline Aluno & Transcrição \\
\hline A19 & $\begin{array}{l}\text { As aulas online são completamente diferentes da aula presencial sendo assim dificulta muito a } \\
\text { aprendizagem. }\end{array}$ \\
A20 & Na aula online, seja de Física ou de qualquer outra matéria, é mais complicado de aprender. \\
& $\begin{array}{l}\text { O que é mais preciso, são exercícios usando um aplicativo durante aula para ficar mais fácil do } \\
\text { aluno ficar atento e aprender, mais exercícios durante aula e menos como tarefa, fazer com o } \\
\text { professor dê confiança e calma ao aluno, deixar em alguns casos o aluno fazer e depois o } \\
\text { professor corrigir é bom (durante a aula também). }\end{array}$ \\
& $\begin{array}{l}\text { Nessa pandemia do jeito que estão as aulas está muito difícil ainda mais para quem nunca tinha } \\
\text { visto alguma matéria ainda. }\end{array}$ \\
A22 & Tem alguns alunos que tem dificuldade nesta matéria e acaba não tendo nenhuma aprendizagem.
\end{tabular}

Quadro 5 - Relatos de alunos quanto à dificuldade na aprendizagem.

Fonte: Elaborada pelos autores.

A ausência da presença física do professor, ou seja, a impossibilidade do contato direto dele com os alunos em sala de aula, favorecendo as interações na maneira tradicional como conhecemos, é uma dificuldade bastante acentuada, com 11 respostas na segunda subcategoria. Percebe-se, assim, o quanto é importante o papel do professor atuando de forma presente frente ao aluno, auxiliando nos seus questionamentos, no direcionamento das atividades propostas, nas tomadas de decisões e na liberdade que o aluno tem para manifestar suas dúvidas e angústias durante as aulas, pois o professor constitui um agente articulador e mediador nesse processo.

Segundo Gil (2008), a relação que o professor possui em sala de aula com seus alunos contribuirá para que os discentes possam manifestar suas declarações e ajudar na formação de seus pensamentos. A insatisfação quanto a ausência da presença física do professor é percebida pelos relatos mostrados a seguir no Quadro 6.

\begin{tabular}{|c|c|}
\hline Aluno & Transcrição \\
\hline $\mathbf{A}_{24}$ & $\begin{array}{l}\text { Considero que sem um professor te explicando cara a cara fica difícil entender a matéria, em } \\
\text { minha opinião. }\end{array}$ \\
\hline $\mathbf{A}_{25}$ & Nenhuma tecnologia do mundo é capaz de substituir um professor em sala de aula. \\
\hline $\mathbf{A}_{26}$ & $\begin{array}{l}\text { Entender sem ter um professor presente pra nos auxiliar, sem todo mundo saber das suas dúvidas } \\
\text { e ajudar a resolve-las, é muito ruim. }\end{array}$ \\
\hline $\mathbf{A}_{27}$ & $\begin{array}{l}\text { Preciso de um professor explicando a matéria, poderia ser, por exemplo, uma vídeo conferência } \\
\text { pelo Google meet. }\end{array}$ \\
\hline A28 & $\begin{array}{l}\text { A maior dificuldade creio eu, é não ter professores explicando seus conteúdos de forma } \\
\text { presencial, prejudicando toda a matéria. }\end{array}$ \\
\hline
\end{tabular}

Quadro 6 - Insatisfação dos alunos em relação à falta da presença física do professor.

Fonte: Elaborada pelos autores. 
Outro problema enfrentado por alguns alunos é a falta de concentração durante as aulas online, onde os professores precisam estimulá-los a manterem o foco e atenção em seus estudos. De-Nardin e Sordi (2009) destacam que a atenção é uma condição fundamental para a aprendizagem, pois quanto maior o foco em determinado objeto, maiores as chances de sucesso, aspecto presente na terceira subcategoria.

O Quadro 7 destaca que a falta de atenção é um fator presente no decorrer das aulas.

\begin{tabular}{|c|c|}
\hline Aluno & Transcrição \\
\hline $\mathbf{A}_{29}$ & Dentro de casa você se distrai fácil com as coisas e perde a concentração. \\
\hline A30 & $\begin{array}{l}\text { Acho uma matéria muito complexa, já é difícil aprender em aula presencial, em EAD então essa } \\
\text { dificuldade triplica. }\end{array}$ \\
\hline $\mathbf{A}_{31}$ & Focar na aula é complicado, muitos fatores externos tiram a atenção. \\
\hline A32 & Minha maior dificuldade é a falta de atenção, pois disperso muito fácil. \\
\hline $\mathbf{A}_{33}$ & $\begin{array}{l}\text { Concentrar-me, sou muito distraída, nas aulas presenciais não acontece de me distrair tanto, e } \\
\text { também no zoom tem o chat onde a turma fica conversando isso atrapalha muito. }\end{array}$ \\
\hline
\end{tabular}

Quadro 7 - Relato dos alunos sobre a falta de atenção durante as aulas online.

Fonte: Elaborada pelos autores.

Na subcategoria quatro apenas um aluno relatou problemas para acessar as plataformas digitais, dificuldade que pode estar relacionada com a falta do dispositivo eletrônico, acesso à internet ou incompatibilidade do celular e ou computador para acessar as plataformas. A inclusão digital deveria abarcar estudantes de todas as classes sociais, sendo importante que sejam adotadas políticas públicas com aportes financeiros visando a possibilitar a inclusão e equiparação de oportunidades a todos os alunos. Para Demo (2007), "a apropriação e inclusão/exclusão de oportunidades e vantagens, as chances de cada pessoa e sociedade é amplamente influenciada pelo acesso tecnológico, em especial ao mundo digital” (DEMO, 2007, p. 6). A manifestação no Quadro 8 retrata a visão do aluno.

\begin{tabular}{|cl|}
\hline Aluno & Transcrição \\
\hline $\mathbf{A 3 4}$ & $\begin{array}{c}\text { A maioria dos alunos não tem acesso a plataformas virtuais e encontram dificuldades em } \\
\text { aprender e acompanhar o conteúdo. }\end{array}$ \\
\hline
\end{tabular}

Quadro 8 - Manifestação sobre o acesso a plataformas digitais.

Fonte: Elaborada pelos autores.

Na segunda questão foi questionado "Quais são suas maiores dificuldades, durante as aulas online de Física, no período da pandemia? Justifique.”. A Tabela 2 apresenta as categorias e subcategorias de análise elaboradas. 
Tabela 2 - Maiores dificuldades durante as aulas online de Física no período da pandemia.

\begin{tabular}{c|c|c|c}
\hline Categorias & Subcategorias & No de respostas & Total \\
\hline \multirow{2}{*}{$\begin{array}{c}\text { Aquisição do } \\
\text { conhecimento }\end{array}$} & Compreender o conteúdo abordado & 69 & 83 \\
\cline { 2 - 4 } & Explicações do professor na sala de aula & 14 & 21 \\
\hline \multirow{2}{*}{$\begin{array}{c}\text { Participação nas } \\
\text { aulas }\end{array}$} & Falta de concentração & 18 & \multirow{2}{*}{03} \\
\hline & Vergonha de tirar dúvidas & 13 & 13 \\
\hline
\end{tabular}

Fonte: dos autores.

Desse questionamento emergiram duas categorias, a primeira delas refere-se à aquisição do conhecimento, na qual muitos alunos relataram grande dificuldade para compreender os conteúdos abordados durante as aulas e também a ausência da presença do professor em sala de aula. A outra categoria diz respeito à participação nas aulas, ou seja, a falta de concentração e a vergonha por parte dos alunos em sanar possíveis dúvidas.

$\mathrm{Na}$ primeira subcategoria, 69 alunos manifestaram dificuldades em compreender o conteúdo proposto durante as aulas online, principalmente nos assuntos relacionados à Física. Uma possibilidade para minimizar este problema é trabalhar com temáticas que possam dar oportunidade para que o estudante debata de forma reflexiva e ativa fazendo relações dos conteúdos e temas com o seu mundo vivenciado, possibilitando o seu enriquecimento a partir de discussão entre os pares, sanando possíveis dúvidas e dificuldades acerca dos temas trabalhados. Neste sentido, Lacerda e Silva (2015) salientam ser fundamental que o professor selecione e planeje atividades que possam auxiliar os alunos na construção do conhecimento e valorizar as contribuições de cada um, respeitando suas opiniões e suas dificuldades.

Uma outra alternativa é a implantação de um viés interdisciplinar que possa facilitar a compreensão das interfaces entre os conteúdos das disciplinas que constituem os currículos tradicionais das escolares, favorecendo assim a aprendizagem dos estudantes.

No Quadro 9 constam relatados dos alunos acerca da dificuldade em compreenderem os conteúdos de Física trabalhados pelos professores. 


\begin{tabular}{|c|c|}
\hline Aluno & Transcrição \\
\hline A35 & $\begin{array}{l}\text { Não absorvemos a matéria direito, e as aulas tão sendo "tocadas" para frente como se nós } \\
\text { estivéssemos entendendo tudo. }\end{array}$ \\
\hline $\mathbf{A}_{36}$ & $\begin{array}{l}\text { Dificuldade de compreensão, pois é muito difícil entender essa matéria através de recursos } \\
\text { tecnológicos. }\end{array}$ \\
\hline $\mathbf{A}_{37}$ & $\begin{array}{l}\text { A Física é uma matéria bem difícil para alguns alunos, aprender pela internet não gera um } \\
\text { resultado melhor do que presencial. }\end{array}$ \\
\hline A38 & $\begin{array}{l}\text { Eu infelizmente não sinto nem um interesse por Física, o que gera uma dificuldade no meu } \\
\text { aprendizado. }\end{array}$ \\
\hline A39 & $\begin{array}{l}\text { Não ter a aula gravada para depois rever para entender o que quase sempre passa despercebido } \\
\text { por ter que ficar horas ao computador. }\end{array}$ \\
\hline
\end{tabular}

Quadro 9 - Dificuldade dos alunos em compreenderem o conteúdo trabalhado.

Fonte: Elaborada pelos autores.

Outro ponto destacado por 14 alunos foi a importância das explicações dos conteúdos serem feitas em sala de aula com a presença do professor. Percebe-se que os alunos consideraram de grande importância estarem inseridos em sala de aula onde os professores encontram-se presentes. Para Haydt (2006, p.55) "é no contexto da sala de aula, no convívio diário com o professor e com os colegas, que o aluno vai paulatinamente exercitando hábitos, desenvolvendo atitudes, assimilando valores". A inserção dos alunos no ambiente escolar demanda do professor atuar como um facilitador que colabora com a sua formação, transmitindo segurança e preparando-os para enfrentarem as questões sociais, ambientais e de seu mundo do trabalho, com o que podem contribuir as abordagens interdisciplinares.

Algumas angústias apontadas pelos alunos podem ser observadas no Quadro 10, que destaca a importância da inserção do aluno no ambiente escolar.

\begin{tabular}{|c|c|}
\hline Aluno & Transcrição \\
\hline A40 & $\begin{array}{l}\text { Eu aprendo mais nas aulas presenciais, não consigo entender muito por whatsapp ou pelo zoom } \\
\text { e muito menos pelo Google meet. }\end{array}$ \\
\hline $\mathbf{A}_{41}$ & $\begin{array}{l}\text { A explicação pelas aulas presenciais são melhores, ao menos para mim, não consegui me adaptar } \\
\text { com o método a distância. }\end{array}$ \\
\hline $\mathbf{A}_{42}$ & $\begin{array}{l}\text { Aula presencial é mais fácil de entender o conteúdo e tirar as dúvidas dentro da sala de aula } \\
\text { ajuda bastante. }\end{array}$ \\
\hline A43 & Sem um professor te explicando cara a cara fica difícil entender a matéria. \\
\hline $\mathbf{A}_{44}$ & $\begin{array}{l}\text { Acho muito complicado ter que aprender Física sem o auxílio presencial de um professor. E deve } \\
\text { ter alunos que não conseguem achar muito sobre a matéria ou têm dificuldade de aprender. }\end{array}$ \\
\hline
\end{tabular}

Quadro 10 - o problema da falta de presença física dos professores durante as aulas.

Fonte: Elaborada pelos autores.

Na segunda categoria, 21 alunos enumeraram problemas com a participação nas aulas, sendo a falta de concentração apontada por 18 deles e a vergonha em tirar dúvidas por 3 
participantes. Adotar posturas docentes diferenciadas de forma que despertem nos estudantes o interesse e a autonomia para exporem com liberdade suas opiniões durante as aulas é um caminho adequado e promissor capaz de despertar a atenção e o interesse dos alunos, mantendo seu foco e concentração nas aulas e atividades propostas. A maior concentração dos alunos pode-se dar também na medida em que são abordados temas envolvendo controvérsias científicas e tecnológicas e questões ambientais e sociais relacionadas com a realidade vivenciada pelos estudantes. Neste sentido, Firme e Amaral (2011, p. 384) defendem que os "conhecimentos científicos e tecnológicos no contexto social, tem o objetivo de preparar cidadãos capacitados para julgar e avaliar as possibilidades, limitações e implicações do desenvolvimento científico e tecnológico".

Por sua vez, a vergonha em participar das aulas, a timidez e outros fatores semelhantes atrapalham o desenvolvimento pedagógico e social dos estudantes, afetando sua interação com os colegas e com os professores. Souza (2011) considera que a timidez é um desconforto que pode trazer várias consequências para as pessoas, principalmente pela preocupação em ser julgado negativamente. Portanto, a ajuda e a segurança proporcionadas pelo professor a esses alunos poderão contribuir para o seu desenvolvimento emocional e garantir maior autoconfiança para participar durante as aulas.

No Quadro 11 são apresentadas algumas transcrições das falas de alunos retratando a vergonha em participarem das aulas.

\begin{tabular}{|cl|}
\hline Aluno & Transcrição \\
\hline $\mathbf{A 4 5}$ & $\begin{array}{l}\text { Às vezes ter vergonha de perguntar devido a outros colegas e a falta de contato com o professor } \\
\text { muda muito o estilo do ensino. }\end{array}$ \\
$\mathbf{A} 46$ & $\begin{array}{l}\text { Aprender Física a distância é um grande desafio principalmente para nós do terceiro ano, além } \\
\text { disso a vergonha em participar das aulas atrapalha muito. }\end{array}$ \\
$\mathbf{A 4 7}$ & Deixo a câmera desligada e o microfone também, para o professor não me ver, fico com vergonha. \\
\hline
\end{tabular}

Quadro 11 - Relato sobre as dificuldades apresentadas nas aulas online. Fonte: Elaborada pelos autores.

A falta de concentração durante as aulas também é um fator destacado pelos alunos e eles mesmos consideraram como um fator que atrapalhou muito durante as aulas. O Quadro 12 relata algumas falas de alunos. 


\begin{tabular}{|cl|}
\hline Aluno & Transcrição \\
\hline $\mathbf{A 4 8} \quad \begin{array}{l}\text { Concentração e falta de vontade não são possíveis nesse tipo de ambiente escolar, ocorre muitas } \\
\text { distrações. Além disso, para quem não possui muita afinidade torna-se ainda mais desmotivador } \\
\text { com a junção de todos esses fatores. }\end{array}$ \\
$\quad \begin{array}{l}\text { Não é muito eficiente para alunos que já encontram dificuldade na matéria, pois precisa de uma } \\
\text { atenção especial e esse tipo de método não abre essa exceção. Contando também com a atenção } \\
\text { que é desviada facilmente. }\end{array}$
\end{tabular}

Quadro 12 - Relato sobre as dificuldades em concentrar nas aulas online.

Fonte: Elaborada pelos autores.

A terceira e última questão diz respeito ao comportamento dos estudantes ser afetado pelas tecnologias, apresentando a seguinte pergunta: "Nesse período de pandemia, você considera que a tecnologia modificou o comportamento dos estudantes durante as aulas? Justifique.”. A tabela 3 apresenta as categorias e subcategorias de análise provenientes das respostas dos alunos.

Tabela 3 - Modificações de comportamento dos estudantes em decorrência das tecnologias.

\begin{tabular}{|c|c|c|c|}
\hline Categorias & Subcategorias & $\mathrm{N}^{\mathrm{o}}$ de respostas & Total \\
\hline \multirow{2}{*}{ Comprometimento } & Maior interesse e responsabilidade & 41 & \multirow{2}{*}{54} \\
\hline & Falta de responsabilidade & 13 & \\
\hline $\begin{array}{c}\text { Relação aluno/ } \\
\text { professor }\end{array}$ & Redução da participação e interação nas aulas & 36 & 36 \\
\hline
\end{tabular}

Fonte: dos autores.

A primeira categoria refere-se ao comprometimento dos alunos, com 54 respostas, na qual surgiram subcategorias referentes ao maior interesse e responsabilidade por parte deles pelas aulas durante a pandemia, 41 respostas, e também o oposto, ou seja, a falta de responsabilidade ou compromisso com as aulas, presente em 13 respostas.

A pandemia de Covid-19 proporcionou mudanças no cenário educacional brasileiro, fortalecendo o papel da Tecnologia como um recurso útil nos diversos níveis da Educação, contribuindo para tornar muitos alunos mais autônomos e responsáveis quanto às atividades propostas. Araújo (2005, p. 23-24) afirma que "o valor da tecnologia na educação é derivado inteiramente da sua aplicação. Saber direcionar o uso da Internet deve ser uma atividade de responsabilidade [...]". Portanto, esse direcionamento e utilização dos recursos tecnológicos poderá contribuir para a formação de alunos responsáveis e engajados em suas atividades diárias, favorecendo a sua aprendizagem dos conteúdos escolares. 
O Quadro 13 mostra que alguns alunos tornaram-se mais responsáveis no período da pandemia frente às aulas online.

\begin{tabular}{|c|c|}
\hline Aluno & Transcrição \\
\hline A50 & $\begin{array}{l}\text { Sim, temos que prestar mais atenção, e ler mais no livro, pois a explicação do professor nem } \\
\text { sempre é o necessário e as vezes uma vídeo aula faz com que o aluno fixe e tire dúvidas mais fácil } \\
\text { do que com as tarefas. }\end{array}$ \\
\hline$A_{51}$ & $\begin{array}{l}\text { Sem dúvidas, muitos alunos tiveram que adaptar suas rotinas de estudo, seus locais de estudo e } \\
\text { até mesmo as fontes de organização para aprender. }\end{array}$ \\
\hline A52 & $\begin{array}{l}\text { Apesar de não se igualar as aulas presenciais, são muito úteis e acredito que estamos tirando o } \\
\text { maior proveito possível. }\end{array}$ \\
\hline $\mathbf{A}_{53}$ & $\begin{array}{l}\text { Agora para aprender tem que correr atrás dos vídeos e exercícios, então boa parte dos alunos } \\
\text { estão realmente estudando agora. }\end{array}$ \\
\hline A54 & $\begin{array}{l}\text { Acredito que muitos descobriram um novo mundo ao procurar aulas e exercícios on-line, já que } \\
\text { as aulas presenciais os acomodavam um pouco. }\end{array}$ \\
\hline
\end{tabular}

Quadro 13 - Relato sobre o aumento do interesse pelas aulas e atividades online.

Fonte: Elaborada pelos autores.

Um ponto interessante identificado na pesquisa foi o fato de que 13 alunos não se mostraram comprometidos com as atividades propostas durante as aulas na modalidade online, sinalizando que o comportamento deles não foi adequado no período de pandemia em relação ao uso da Tecnologia.

Cavalcante et al. (2016, p.139) considera que "para os alunos, que vivem em um mundo dinâmico e em constantes transformações, a escola é vista, na maioria das vezes, como um local desinteressante, entediante e não prazeroso". Nas manifestações a seguir, ficou explícito o desinteresse e a falta de comprometimento de alguns estudantes.

\begin{tabular}{|c|c|}
\hline Aluno & Transcrição \\
\hline A55 & $\begin{array}{l}\text { Modificou para pior, pois alguns alunos não tem responsabilidade e disciplina. E é horrível } \\
\text { estudar tudo pelo computador ou celular porque você pode fazer muitas coisas além de estudar e } \\
\text { isso atrapalha quando o aluno quer parar e estudar. }\end{array}$ \\
\hline A56 & Sim, pois muitos alunos levam na brincadeira e acham que não são aulas de verdade. \\
\hline A57 & $\begin{array}{l}\text { Muitos nem estão fazendo as atividades necessárias, se não ligam nas aulas normais, imagina } \\
\text { agora na online. }\end{array}$ \\
\hline A58 & $\begin{array}{l}\text { Muita gente não está estudando como na sala de aula, e acabam pesquisando no Google é não } \\
\text { aprende nada. }\end{array}$ \\
\hline $\mathbf{A}_{59}$ & A maioria agora pratica a auto sabotagem e consequentemente a diminuição do aprendizado. \\
\hline
\end{tabular}

Quadro 14 - Falta de comprometimento dos alunos durante as aulas.

Fonte: Elaborada pelos autores. 
A segunda categoria refere-se a relação entre o aluno e o professor, com 36 respostas. Dessa categoria emergiu a subcategoria redução da participação e interação nas aulas. Diante dessa problemática, o professor poderá mudar sua forma de abordar os conteúdos propostos, buscando atuar de modo a estimular uma participação efetiva de seus alunos capaz de ampliar seus horizontes culturais e permitindo, ainda, intensificar a relação entre o professor e os alunos. De acordo com Guimarães (2001), é importante que o professor seja sensível às necessidades internas e perspectivas pessoais do aluno e propicie um clima encorajador de iniciativa e de participação. A diminuição da interação aluno/professor fica clara nos depoimentos dos alunos mostrados no quadro a seguir.

\begin{tabular}{|cl|}
\hline Aluno & Transcrição \\
\hline $\mathbf{A}_{60}$ & $\begin{array}{l}\text { A única diferença real para mim é que os alunos ficam mais calados nas aulas virtuais. } \\
\mathbf{A}_{61}\end{array}$ \\
$\begin{array}{l}\text { Sim, nas minhas aulas online quando um professor faz uma pergunta para um aluno ele fica quieto } \\
\text { ou as vem está assistindo a aula de verdade. }\end{array}$ \\
$\begin{array}{l}\text { A comunicação foi dificultada, pelo menos pra mim não consigo me concentrar tanto nas aulas e } \\
\text { acabo ficando perdida na maioria das vezes. }\end{array}$ \\
$\begin{array}{l}\text { Nas reuniões por vídeo os alunos ficam mais quietos e um pouco menos participativos em algumas } \\
\text { aulas, principalmente nas matérias que envolvem mais a leitura e entendimento. }\end{array}$ \\
$\mathbf{A}_{64}$ & Infelizmente não falo com o professor durante as aulas e minhas dúvidas estão só aumentando. \\
\hline
\end{tabular}

Quadro 15 - Redução da interação aluno/professor durante as aulas.

Fonte: Elaborada pelos autores.

Entendemos que essas dificuldades de interação apontadas pelos alunos podem ser superadas ou minimizadas na medida em que os professores melhor se adaptem às condições impostas pelo uso sistemático dos recursos tecnológicos em suas aulas, implementando mudanças na sua forma de lecionar e conduzir as atividades, pois é compreensível que muitos deles não estavam familiarizados com este cenário de uso mais intenso da tecnologia. Assim, sendo obrigados a aprender a trabalhar com as ferramentas tecnológicas em suas aulas, é preciso que os professores se capacitem e busquem promover motivação, envolvimento e a almejada aprendizagem nos estudantes, ainda que a tecnologia possa ser vista por muitos docentes como uma fonte de desconforto e insegurança.

\section{CONSIDERAÇÕES FINAIS}

O estudo exploratório apresentado aqui permitiu alcançar um conhecimento mais amplo acerca de alguns aspectos relacionados com a realidade vivida pelos alunos no que diz respeito 
às aulas ministradas durante a pandemia, permitindo compreender suas angústias, dificuldades e também os pontos positivos da nova maneira de ensinar que emergiu deste complexo contexto sanitário.

Diante deste cenário que ampliou os desafios colocados à atividade docente e também para o processo de aprendizagem dos estudantes, sendo caracterizado por restrições as aglomerações e, portanto, com impactos significativos sobre as atividades realizadas nos ambientes escolares, estabelecemos como objetivo de pesquisa buscar respostas para nossa questão de investigação, ou seja, "Quais são as percepções dos estudantes de escolas públicas e privadas quanto ao uso de recursos tecnológicos pelos professores durante o período da pandemia de Covid-19?"

As falas dos alunos apontaram que os recursos tecnológicos podem trazer benefícios para as aulas e para os processos de ensino e aprendizagem, uma vez que favorecem o acesso as informações necessárias para a realização de pesquisas, ampliam as possibilidades de acesso aos recursos da internet e permitem a utilização das redes sociais para comunicação com os professores, favorecendo as interações. Porém, algumas respostas dos estudantes apontam que o uso dos recursos tecnológicos atrapalha seu desempenho e concentração no decorrer das aulas, prejudicando seu rendimento escolar e a compreensão dos conteúdos abordados, afetando a aprendizagem.

Outro fator que merece destaque foi em relação ao comprometimento, pois embora uma parte considerável dos alunos tenha destacado que se encontra comprometida e engajada com as aulas, uma outra parcela considera que a participação foi reduzida durante as aulas online, afetando a relação com o professor que tornou-se mais distante, diminuindo com isso as possibilidades de interação.

Visando minimizar alguns dos problemas apontados pelos estudantes entendemos que os professores podem lançar mão de novas posturas e enfoques em suas atividades docentes, valorizando o que os alunos já conhecem e buscando com frequência contextualizar os conteúdos curriculares, aproximando-os do mundo vivencial dos estudantes, de modo a instigar sua participação nas aulas, motivando-os a interagirem, debaterem e construírem juntos novos conhecimentos, tendo o professor como um mediador e estimulador das atividades e da participação ativa dos alunos.

É importante destacar a diferença entre as realidades vividas pelos alunos que possuem acesso as aulas online e os que tem dificuldades para acompanharem essas aulas. O aluno que possui um computador, um celular ou tablet, acompanhado de internet em casa, terá melhores 
condições para acompanhar as aulas e seguir as orientações dos professores, bem como acompanhar as vídeo aulas que servirão como um complemento das atividades relacionadas com a disciplina, além de poderem acessar outros recursos. Os alunos que não possuírem tais recursos tenderão a ficar defasados em relação aos conteúdos abordados, tendo maiores dificuldades para interagir com os professores e colegas de turma, podendo ficar desmotivados e desinteressados pelas aulas.

Portanto, entendemos que é papel do professor preocupado com a qualidade do processo formativo estimular as interações aluno-professor e aluno-aluno, criando um ambiente capaz de propiciar liberdade para que os estudantes possam analisar as falas dos colegas, refletirem sobre diferentes pontos de vista e tirarem suas próprias conclusões, desenvolvendo paciência e respeito para ouvir e sentindo segurança para opinar e participar, tornando mais produtivo o processo de aprendizagem.

Enfim, os recursos tecnológicos se mostraram úteis e até mesmo necessários no período da pandemia, pois possibilitaram a interação digital entre alunos e professores, que juntos buscaram superar as dificuldades impostas pelo contexto gerado pelo Covid-19, de modo que muitos alunos conseguiram se apropriar dos conhecimentos e conceitos abordados, ainda que seja percebida a necessidade da presença física do professor. De modo geral, as tecnologias e particularmente os recursos da internet quando adequadamente empregados na Educação podem contribuir para que as escolas continuem a desempenhar o seu importante papel social, promovendo a aprendizagem e o desenvolvimento dos educandos.

\section{REFERÊNCIAS}

ALMEIDA, M. E. B.; SILVA, M. G. M. Currículo, tecnologia e cultura digital: espaços e tempos de web currículo. Revistae-Curriculum, v.7, n.1, p.1-19, abr. 2011. Disponível em: https://revistas.pucsp.br/curriculum/article/viewFile/5676/4002/. Acesso em: 10 ago. 2020.

ARAÚJO, U. F. A quarta revolução educacional: a mudança de tempos, espaços e relações na escola a partir do uso de tecnologias e da inclusão social. ETD: educação temática digital, Campinas, v. 12, 2011.

ARAÚJO, R. S. de. Contribuições da Metodologia WebQuest no Processo de letramento dos alunos nas séries iniciais no Ensino Fundamental. In: MERCADO, Luís Paulo Leopoldo (org.). Vivências com Aprendizagem na Internet. Maceió: Edufal, 2005.

AROCENA, R. Riesgo, cambio técnico y democracia en el subdesarrollo. In: LUJÁN, José. L. y ECHEVERRÍA, J. Gobernar los Riesgos: ciencia y valores en la sociedad del riesgo. Madrid: Biblioteca Nueva - OEI, 2004, p. 207-223. Disponível em: 
http://biblioteca.flacso.edu.gt/library/index.php?title=9557\&query=@ title=Special:GSMSearc hPage@process=@ autor=LUJAN,\%20JOSE@mode=\&recnum=12. Acesso em: 20 jun. 2020.

BARDIN, L. Análise de conteúdo. 4. ed. Lisboa: Edições 70, 2010.

BARDIN, L. Análise de conteúdo. São Paulo: Edições 70, 2011.

BAZZO, W. A. Ciência, Tecnologia e Sociedade: e o contexto da educação tecnológica. Florianópolis: Ed. da UFSC, 1998.

BRASIL. Base Nacional Comum Curricular.Brasília: MEC, 2017. Disponível em: http://basenacionalcomum.mec.gov.br/images/BNCC_20dez_site.pdf. Acesso em: 15 jun. de 2020 .

BORUCHOVITCH, E.; BZUNECK, J. A. (orgs.). A motivação do aluno: contribuições da psicologia contemporânea. 3. ed. Petrópolis: Vozes, 2001.

BOTTENTUIT JUNIOR, J. B.; ALBUQUERQUE, O. C. P.; COUTINHO, C. P. Whatsapp e suas aplicações na educação: uma revisão sistemática da literatura. EducaOnline, Rio de Janeiro, v. 10, n. 2, p. 67-87, maio/ago. 2016. Disponível em:

http://www.latec.ufrj.br/revistas/index.php?journal=educaonline\&page=article\&op=view\&pat

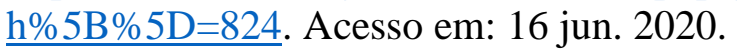

CAVALCANTE, M. B. et al. O ensino de geografia sob um enfoque motivador. Gaia Scientia, João Pessoa, v.10, n.4, p.138-150, set. 2016. Disponível em:

https://periodicos.ufpb.br/ojs/index.php/gaia/article/view/25274. Acesso: 22 jun. 2020.

COSTA, S. M. A influência dos recursos tecnológicos no processo de ensino aprendizagem. 2014. 43f. Trabalho de Conclusão de Curso (Especialização em Fundamentos da Educação: Práticas Pedagógicas Interdisciplinares)- Universidade Estadual da Paraíba, Sousa, 2014. Disponível em: http://dspace.bc.uepb.edu.br/jspui/handle/123456789/6619. Acesso: 22 jun. 2020.

DALlACOSTA, A.; TAROUCO, L. M. R.; DUTRA, R. L. de S. A Utilização da Indexação de Vídeos com MPEG-7 e sua Aplicação na Educação. RENOTE. Revista Novas Tecnologias na Educação, v. 2, p. 1-10, 2004. Disponível em: file://C:/Users/vilel/AppData/Local/Temp/13725-48540-1-PB.pdf. Acesso em: 04 nov. 2020.

DE-NARDIN, M. H.; SORDI, R. Aprendizagem da atenção: uma abertura à invenção. Revista Semestral da Associação Brasileira de Psicologia Escolar e Educacional (ABRAPEE), v. 13, n. 1, p. 97-106, 2009. Disponível em: https://www.scielo.br/pdf/pee/v13n1/v13n1a11. Acesso: 30 jun. 2020.

DEMO, P. Marginalização Digital: digital divide. In: Boletim Técnico do SENAC, v. 33, p. 5-19, 2007. Série: 2. Disponível em: https://www.bts.senac.br/bts/article/view/295. Acesso: 30 jun. 2020.

DE-NARDIN, M. H.; SORDI, R. O. Aprendizagem da atenção: uma abertura à invenção. Revista Iberoamericana de Educación, Porto Alegre, v.47, n.4, p. 1-11, nov. 2008. 
Disponível em:

https://www.researchgate.net/publication/28231071_Aprendizagem_da_atencao_uma_abertur a_a_invencao. Acesso: 05 ago. 2020.

FIRME, R. N.; AMARAL, E. M. R. Analisando a implementação de uma abordagem CTS na sala de aula de química. Revista Ciência \& Educação, v. 17, n. 2, p. 383-399, 2011.

Disponível em: https://www.scielo.br/pdf/ciedu/v17n2/a09v17n2.pdf. Acesso: 16 jun. 2020.

GIL, Antônio Carlos. Métodos e técnicas de pesquisa social. 5. ed. São Paulo: Atlas, 1999.

GUIMARÃES, S.E.R. Motivação intrínseca, extrínseca e o uso de recompensas em sala de aula. Em Boruchovitch, E.; Bzuneck, J.A. (Orgs.), Motivação do aluno: Contribuições da psicologia contemporânea, Petrópolis: Editora Vozes, 2001.

HAYDT, Célia Regina. Curso de didática geral. $8^{\circ}$ ed. São Paulo: Ática, 2006.

KENSKI, V. M. Educação e tecnologia: o novo ritmo da informação. 3 ed. Campinas, SP. Papirus, 2007. Coleção Papirus Educação.

LACERDA, A. L. de; SILVA, T. da. Materiais e estratégias didáticas em ambiente virtual de aprendizagem. Rev. bras. Estud. pedagog. (online), Brasília, v. 96, n. 243, p. 321-342, 2015. Disponível em: https://www.scielo.br/pdf/rbeped/v96n243/2176-6681-rbeped-96-24300321.pdf. Acesso: 10 ago. 2020.

MERCADO, Luís Paulo Leopoldo (org.). Vivências com Aprendizagem na Internet. Maceió: Edufal, 2005.

MORAES, J. U. P.; ARAÚJO, M. S. T. O Ensino de Física e o Enfoque CTSA: Caminhos para uma educação cidadã. São Paulo-SP, Livraria da Física, 2012, 144 p.

MORAN, José Manuel et al. Novas Tecnologias e mediação pedagógica. 6. Ed., Campinas, Papirus, 2000.

MORAN, José Manoel. Desafios na comunicação pessoal: gerenciamento integrado da comunicação pessoal, social e tecnológica. 3. ed. São Paulo: Paulinas, 2007b, p. 162-166. Disponível em:

http://www.eca.usp.br/prof/moran/site/textos/tecnologias_eduacacao/midias_educ.pd. Acesso em: 5 nov. 2020.

SANTOS, M. E. V. M. Cidadania, conhecimento, ciências e educação CTS. Rumo a "novas" dimensões epistemológicas. Revista CTS, v.2, n. 6, 2005. Disponível em: https://www.redalyc.org/pdf/924/92420606.pdf. Acesso: 20 jun. 2020.

SANTOS, W. L. P. dos. et al. Formação de professores: uma proposta de pesquisa a partir da reflexão sobre a prática docente. Rev. Ensaio, Belo Horizonte, v.08, n.01, p.69-82. jan-jun 2006. Disponível em: https://www.scielo.br/pdf/epec/v8n1/1983-2117-epec-8-01-00069.pdf. Acesso: 10 ago. 2020. 
SANTOS, W. L. P.; MORTIMER, E. F. Uma análise de pressupostos teóricos da abordagem C-T-S (Ciência - Tecnologia - Sociedade) no contexto da educação brasileira. Rev. Ensaio, Belo Horizonte, v.02 | n.02, p.110-132. Jul-dez 2000. Disponível em:

https://www.scielo.br/pdf/epec/v2n2/1983-2117-epec-2-02-00110.pdf. Acesso: 05 ago. 2020.

SEE/MG. Currículo Referência de Minas Gerais. Belo Horizonte, 2019. Disponível em: http://basenacionalcomum.mec.gov.br/images/implementacao/curriculos_estados/documento curricular_mg.pdf. Acesso: 19 jun. 2020.

SOUZA, K. C. C. A Timidez Como Entrave Emocional Patológico: levantamento quantiqualitativo dos relatos de pacientes atendidos na clínica-escola de Psicologia em uma faculdade da rede privada. Visão Acadêmica. Universidade Estadual de Goiás. Mai. 2011. Disponível em: https://www.yumpu.com/pt/document/read/12759282/revista-visaoacademica-ueg. Acesso: 10 ago. 2020.

SOUZA, J de R. PATARO, P.R.M. Vontade de saber Matemática. $1^{\text {a }}$ Ed. São Paulo: FTD, 2009.

STRIEDER, R. B.; WATANABE-CARAMELL, G.; GEHLE, S. T. Abordagem de temas no Ensino Médio: compreensões de professores de Física. Revista Ensaio, Belo Horizonte, v.14, n. 02, p. 153-169. Ago-nov. 2012. Disponível em:

https://www.scielo.br/pdf/epec/v14n2/1983-2117-epec-14-02-00153.pdf. Acesso: 20 jun. 2020.

STRIEDER, R. B; WATANABE, G; SILVA, K. M. A. e; WATANABE. G. Educação CTS e Educação Ambiental: Ações na Formação de Professores. ALEXANDRIA Revista de Educação em Ciência e Tecnologia, v.9, n.1, p.57-81, maio 2016. Disponível em: https://periodicos.ufsc.br/index.php/alexandria/article/view/1982-5153.2016v9n1p57. Acesso: 25 jun. 2020.

TONETTO, L. M. et al. Perspectivas Metodológicas na Pesquisa Sobre o Comportamento do Consumidor. PSICOLOGIA: CIÊNCIA E PROFISSÃO, v. 34, n.1, p. 180-195, 2014.

Disponível em: v34n1a13.pdf (scielo.br). Acesso: 18 fev. 2021.

VIEIRA, V. A. As tipologias, variações e características da pesquisa de marketing. Rev. FAE, Curitiba, v. 5, n. 1, p.61-70, jan./abr. 2002.

\section{APÊNDICE 1}

\section{AGRADECIMENTOS}

Agradecemos ao apoio concedido pela Coordenação de Aperfeiçoamento de Pessoal de Nível Superior (CAPES).

FINANCIAMENTO

O presente trabalho foi realizado com apoio da Coordenação de Aperfeiçoamento de Pessoal de Nível Superior Brasil (CAPES).

\section{CONTRIBUIÇÕES DE AUTORIA}


Resumo/Abstract/Resumen: Jean Louis Landim Vilela; Anderson Claiton Ferraz; Mauro Sérgio Teixeira de Araújo Introdução: Jean Louis Landim Vilela; Anderson Claiton Ferraz; Mauro Sérgio Teixeira de Araújo Referencial teórico: Jean Louis Landim Vilela; Anderson Claiton Ferraz; Mauro Sérgio Teixeira de Araújo Análise de dados: Jean Louis Landim Vilela; Anderson Claiton Ferraz; Mauro Sérgio Teixeira de Araújo Discussão dos resultados: Jean Louis Landim Vilela; Anderson Claiton Ferraz; Mauro Sérgio Teixeira de Araújo Conclusão e considerações finais: Jean Louis Landim Vilela; Anderson Claiton Ferraz; Mauro Sérgio Teixeira de Araújo

Referências: Jean Louis Landim Vilela; Anderson Claiton Ferraz; Mauro Sérgio Teixeira de Araújo Revisão do manuscrito: Jean Louis Landim Vilela; Anderson Claiton Ferraz; Mauro Sérgio Teixeira de Araújo Aprovação da versão final publicada: Jean Louis Landim Vilela; Anderson Claiton Ferraz; Mauro Sérgio Teixeira de Araújo

\section{CONFLITOS DE INTERESSE}

Os autores declararam não haver nenhum conflito de interesse de ordem pessoal, comercial, acadêmico, político e financeiro referente a este manuscrito.

\section{DISPONIBILIDADE DE DADOS DE PESQUISA}

O conjunto de dados que dá suporte aos resultados da pesquisa foi publicado no próprio artigo.

\section{CONSENTIMENTO DE USO DE IMAGEM}

Não se aplica.

\section{APROVAÇÃO DE COMITÊ DE ÉTICA EM PESQUISA}

Não se aplica.

\section{COMO CITAR - ABNT}

VILELA, Jean Louis Landim. FERRAZ, Anderson Claiton. ARAÚJO, Mauro Sérgio Teixeira de. Utilização de Recursos Tecnológicos nas aulas de Física como forma de superar as dificuldades impostas pela Pandemia da Covid-19. REAMEC - Rede Amazônica de Educação em Ciências e Matemática. Cuiabá, v. 9, n. 2, e21047, maio-agosto, 2021. http://dx.doi.org/10.26571/reamec.v9i2.11470.

\section{COMO CITAR - APA}

VILELA, J. L. L. FERRAZ, A. C. ARAÚJO, M. S. T. (2021). Utilização de Recursos Tecnológicos nas aulas de Física como forma de superar as dificuldades impostas pela Pandemia da Covid-19. REAMEC - Rede Amazônica de Educação em Ciências e Matemática, 9 (2), e21047. http://dx.doi.org/10.26571/reamec.v9i2.11470.

\section{LICENÇA DE USO}

Licenciado sob a Licença Creative Commons Attribution-NonCommercial 4.0 International (CC BY-NC 4.0). Esta licença permite compartilhar, copiar, redistribuir o manuscrito em qualquer meio ou formato. Além disso, permite adaptar, remixar, transformar e construir sobre o material, desde que seja atribuído o devido crédito de autoria e publicação inicial neste periódico.

\section{DIREITOS AUTORAIS}

Os direitos autorais são mantidos pelos autores, os quais concedem à Revista REAMEC - Rede Amazônica de Educação em Ciências e Matemática - os direitos exclusivos de primeira publicação. Os autores não serão remunerados pela publicação de trabalhos neste periódico. Os autores têm autorização para assumir contratos adicionais separadamente, para distribuição não exclusiva da versão do trabalho publicada neste periódico (ex.: publicar em repositório institucional, em site pessoal, publicar uma tradução, ou como capítulo de livro), com reconhecimento de autoria e publicação inicial neste periódico. Os editores da Revista têm o direito de proceder a ajustes textuais e de adequação às normas da publicação.

\section{PUBLISHER}

Universidade Federal de Mato Grosso. Programa de Pós-graduação em Educação em Ciências e Matemática (PPGECEM) da Rede Amazônica de Educação em Ciências e Matemática (REAMEC). Publicação no Portal de Periódicos UFMT. As ideias expressadas neste artigo são de responsabilidade de seus autores, não representando, necessariamente, a opinião dos editores ou da referida universidade.

\section{EDITOR}

Marcel Thiago Damasceno Ribeiro (iD) 9 


\section{HISTÓRICO}

Submetido: 28 de novembro de 2020.

Aprovado: 15 de fevereiro de 2021.

Publicado: 16 de agosto de 2021. 